Archived version from NCDOCKS Institutional Repository - http://libres.uncg.edu/ir/asu/

Spaulding, T.J. (2010) How can virtual communities create value for business? Electronic

Commerce Research and Applications, 9(1): 38-49. Published by Elsevier (ISSN: 1567-4223).

The version of record is available from: http://dx.doi.org/10.1016/j.elerap.2009.07.004

\title{
How can virtual communities create value for business?
}

Trent J. Spaulding

\begin{abstract}
Virtual communities include everything from discussion boards to massive multiplayer online role-playing games and virtual realities such as Second Life. The business world has assumed that virtual communities can be leveraged to provide access to consumers and consumer data. The benefits of this assumption have not always been realized. The purpose of this article is to understand why some business ventures into virtual communities fail and others succeed. Why do virtual communities support certain types of business activities and not others? Which firm activities are the best candidates to benefit from being positioned in virtual communities? The theories of social contracts and trust explain how firms can successfully participate in virtual communities. The theories have implications in the context of transaction-oriented, interestoriented, relationship-oriented, and fantasy-oriented communities. The value chain provides an instructive background to understand which firm activities are candidates for being included in virtual communities. Success in virtual communities depends on an attitude of contribution, dedication of resources, building a critical mass, and matching community and business needs. Because many social technologies are in the disillusionment stage of the hype cycle, further research in the business use of virtual communities is needed to guide business practices as we move to full adoption.
\end{abstract}




\section{INTRODUCTION}

Virtual communities include everything from discussion boards to massive multiplayer online role-playing games (MMORPGs) and virtual realities such as Second Life. The business world has assumed that virtual communities can be leveraged to provide access to consumers and consumer data. The benefits of this assumption have not always been realized. Following Kannan et al., 2000 and Rheingold, 1993, virtual communities are defined as aggregations of Internet users who form webs of personal relationships. The purpose of this research is to understand why some business ventures in virtual communities fail and others succeed. In this research, the definition of a successful venture into a virtual community is acceptance of the firm or firm activity by the community. Community members express rejection of firm activity by ignoring or ostracizing the firm ( Rose, 2007), abandoning the community, or speaking out against the firm ( Jarvis, 2007). Therefore, continued presence and action of a firm in a community is evidence of success. Success could also be defined in terms of positive cash flows. Positive cash flows may come as a direct result of activity in the community. Examples include positive cash flows as a result of participation in eBay, or as an indirect result of outcomes such as marketing and brand recognition (Kerin and Sethuraman, 1998). Because of the lack of data and examples and the theoretical nature of this article, this research must use acceptance of the community as a measurement of success. This article explores two research questions:

- Why do virtual communities accept certain types of business activities and not others?

- Which firm activities are the best candidates to benefit from participation in virtual communities?

Revenue from these virtual communities represents billions of dollars in software sales, subscriptions, and ad revenue. Blizzard Entertainment's revenue pushed over US\$1.2 billion in 2007 due largely to the success of World of Warcraft (Vivendi, 2007). Linden Lab generates much of its revenue through subscriptions and virtual land fees from over 85,000 paying residents (Krangel, 2007). The Second Life economy transacts about US\$ 1.5 million a day in virtual and real goods ( Reuters, 2008). Many more traditional online communities stay profitable by selling ad space or keyword advertising. Still other firms have tried to simply participate in virtual communities. For example, Dell has been successful in moving part of its product support to online communities (DellCommunity, 2008). On the other hand, Wired Magazine ( Rose, 2007) reports that Second Life corporate locations for Coke, Nissan, Pontiac, H\&R Block and others are devoid of virtual life. Much like the dotcom rush, firms have jumped into virtual communities to promote their brands and products without understanding how these communities work and how to use them successfully. Communities such 
as Facebook are creating interfaces for business to create a presence and providing tools for targeted advertising.

To understand why some business activities are accepted and others are not, this research will explore social contracts and trust theory. Every community is subject to social contracts. Community members give up time, money or other resources in exchange for the benefits of the community. In virtual communities, the expectations created by social contracts dictate what a firm can or cannot do. When these social contracts are not upheld, long-term relationships become impossible. The value chain provides a lens to view business activities to increase our understanding of which activities are potential matches for virtual communities.

Section 2 describes the theories of social contracts and trust, and how they relate to each other. Four different types of virtual communities and their social contracts are described. Section 3 discusses how different parts of the value chain are likely to benefit from activities in virtual communities. The final section presents several principles for successful participation in virtual communities and closes by evaluating the impetus for four different categories of future research.

\section{TRUST AND SOCIAL CONTRACTS IN VIRTUAL COMMUNITIES}

The success of a venture into a virtual community will hinge on the ability of the business to work with that community. Virtual communities have their own cultures and expectations. The community stays together by adhering to the values and norms of the group. These expectations come from the social contract. Individuals or groups who do not understand the social contract are often looked on with suspicion and can be excluded from the community. Application of trust theory and social contracts theory explains how and why companies will succeed or fail in working with virtual communities.

\subsection{Social contracts and trust in virtual communities}

\subsubsection{Social contracts}

A social contract is an implicit or explicit agreement to give up rights for other benefits such as power and social relationships ( Rousseau, 1762). Social contracts are often studied in relationship to governance. Governance of an organization is not always a formal bureaucratic process. In many communities the social contract is enforced through the actions or reactions of the members of the community. In virtual communities there are both explicit and implicit rules. Explicit rules often describe how to join the community, how to act as a participant, and why one should be expelled from the community. Implicit rules also govern how a member should participate and often extend to why a member participates. 
Kaufman et al. (2005) are the first to explicitly discuss how social contracts have changed with technology, particularly as it relates to privacy. According to them the social contract is changing at an accelerated pace. For example, the social contract of behavior and interaction in urban communities developed over an extended period as people gradually gave up the privacy and freedom of rural homes and moved to metropolitan areas and factory jobs. Later, social contracts developed around use of the telephone. This social contract specifies that there are certain times which are appropriate to call a neighbor and that close friends have more discretion to call at any time of the day. A solicitation call during an inconvenient time of day may have negative implications for customer relationships as well as legal implications. The social contract of the appropriate and acceptable use of the telephone is well known by the population because of the slow rate of adoption and the extent of adoption of the telephone. This social contract developed much faster than that of urban living. Internet technologies on the other hand are being adopted at breathtaking speeds. The speed of adoption and diffusion has made it difficult for new users to understand the social contract of virtual community technologies. Evidence of the speed of change is the short hype cycles of social software which, from current press, seem to be somewhere between 3 and 7 years (Kee, 2009). A hype cycle describes the initial excitement around a technology followed by disillusionment and finally full adoption.

Because all communities including virtual communities are subject to social contracts (Smith, 1999), trust plays a significant role in the governance of a community. Social contracts generally develop in harmony with the reasons that members join a community. Communities in general have been formed for many reasons including group power (e.g., governments) and recreation (e.g., motorcycle clubs). Virtual communities are a natural extension to this phenomenon. Behavioral expectations are often dictated by the purpose of the community. By allowing a person to become a member of a community, the community is placing some level of trust in that person to benefit, or at least not harm the community. When that trust is broken, members may be removed from the community.

\subsubsection{Trust}

Academic definitions of trust provide two essential points to understanding interactions in a virtual community. First, definitions describe what trust is and when it is required. Second, the theory gives the results of disconfirmation of trust. Trust is more than predictability. Predictability can come from economic incentives or from knowing historically how events have happened. Trust involves vulnerability and expectations. According to an early empirical definition of trust, Person A has trust when he expects Person B to behave in a certain way and that expectation leads Person $A$ to make themselves vulnerable to Person $B$ 's action in a manner that the possible negative outcomes are greater when expectations are disconfirmed than the possible positive outcomes when 
expectations are confirmed (Deutsch, 1958). A community is better off to admit someone they can trust to uphold the social contract than to not admit them. However, if the community's expectation is not confirmed, the community is worse off than it would have been had it not admitted the member. This is obvious in many real-world settings such as the breakup of crime rings. Each individual admitted to a group that benefits from illegal activities provides some marginal benefit to the group if that person confirms the trust of the group. On the other hand, if a member disconfirms the group's trust (i.e., by working with law enforcement), that member may cause significant damage or even destruction of the group. Second Life ad farms provide a virtual community example. Each additional member in Second Life provides the marginal benefit of another character with which to interact. However, some members join Second Life just to create ads for others to see, littering the landscape and violating the atmosphere of the fantasy world (Krangel, 2008a). The atmosphere of the fantasy world is the main attraction for many participants.

Modern definitions of trust (e.g., Ba and Pavlou, 2002, Lewicki et al., 1998, McKnight et al., 2002 and Rousseau et al., 1998) are in line with Deutsch (1958). The most-recognized definition of trust used in e-commerce is given by McKnight et al. (2002). They build on the theory of reasoned action (Fishbein and Ajzen, 1975 ) by using trusting beliefs as an antecedent of trusting intentions and trusting actions. According to McKnight et al. (2002), four basic concepts of trust help to explain online behavior. First, each person has his own disposition to trust. Firms must work harder to gain the trust of individuals and groups that are less inclined to trust. The other three concepts are grouped into trusting beliefs. Trusting beliefs refer to the user's perception of the other party's competence, benevolence and integrity. A user believes the other party has competence when he perceives that the party being trusted is able to accomplish what is promised or inferred. Benevolence refers to a belief that the other party is not acting maliciously. Integrity refers to the belief that the other party will not take unfair advantage of shared information or incomplete contracts. Trusting intentions are a function of the user's disposition to trust and trusting beliefs. A user is more likely to trust if he is more disposed to trust and has a belief that the other party has competence, benevolence and integrity.

\subsection{Types of virtual communities}

As suggested in the telephone example, solicitors can damage trust by using telephones for advertising in a manner that is not congruent with the social contract. Thus the social contract dictates what a business can successfully do in a community. Because social contracts vary between different types of communities, I discuss social contracts and trust as they apply to each type of virtual community. Kannan et al. (2000) divide the virtual community space into four categories (see Table 1). A thorough listing of all the social contracts for each category of community is impossible; nevertheless, there are aspects of social contracts that are common and key to the different types of communities. 
Table 1

Types of communities, sodial contracts and trust issues.

\begin{tabular}{|c|c|c|c|}
\hline Community & Social contracts & Trust issues & Examples \\
\hline $\begin{array}{l}\text { Transaction- } \\
\text { oriented (TO) }\end{array}$ & $\begin{array}{l}\text { - Accurate representation of sales } \\
\text { - Use of information for transactional } \\
\text { purposes }\end{array}$ & $\begin{array}{l}\text { - A very small percentage of poor feedback scores can lead to large } \\
\text { losses in price }\end{array}$ & eBay, craigslist \\
\hline $\begin{array}{l}\text { Interest- } \\
\quad \text { oriented (10) }\end{array}$ & $\begin{array}{l}\text { - Accurate information } \\
\text { - Information must be on topic }\end{array}$ & $\begin{array}{l}\text { - Biased information can cause removal of the firm from the com- } \\
\text { munity and possible damage of the firm's reputation }\end{array}$ & $\begin{array}{l}\text { ParentsPlace, MSDN, Dell } \\
\text { Community }\end{array}$ \\
\hline $\begin{array}{l}\text { Rel ationship- } \\
\text { oriented (RO) }\end{array}$ & $\begin{array}{l}\text { - Use of information for community } \\
\text { purposes } \\
\text { - When participating in the community, } \\
\text { you want others to contact you }\end{array}$ & $\begin{array}{l}\text { - Misuse of information provided by the company can cause dam- } \\
\text { age to the firm's reputation }\end{array}$ & $\begin{array}{l}\text { MyFamily.org. Linkedln, } \\
\text { MySpace }\end{array}$ \\
\hline $\begin{array}{l}\text { Fantasy-oriented } \\
\text { (FO) }\end{array}$ & $\begin{array}{l}\text { - Respect for the purpose of the virtual } \\
\text { community } \\
\text { - Respect for anonymity and privacy }\end{array}$ & $\begin{array}{l}\text { - Lack of respect for the community environment can lead to } \\
\text { abandonment of virtual stores and virtual terrorism }\end{array}$ & $\begin{array}{l}\text { Second Life, World of } \\
\text { Warcraft, Stagecoach Island }\end{array}$ \\
\hline
\end{tabular}

The main function of transaction-oriented communities is to bring sellers and buyers together. Many communities such as eBay.com facilitate completion of the transaction. Others such as CraigsList.org only help members to find one another. Completing the transaction is up to the individuals. Because of the substantial risk associated with transaction making, transaction-oriented communities cannot exist without trust. To reduce risk, participants need to know that the other party has the competence to complete the transaction, has no ulterior motives, and will not act maliciously to harm the other party. Without trust, risk increases and prices deflate causing sellers with valuable goods to take their goods elsewhere. The market becomes a "market for lemons" ( Akerlof, 1970). eBay is easily the most successful consumer-to-consumer auction site on the Internet. Trust is so vital that PayPal was purchased by eBay, in part, to guarantee transaction completion to buyers and sellers. The critical mass that eBay has built makes moving to other auction sites unattractive for many sellers. Therefore, eBay is more likely to function as a market than less well-known sites. The critical mass gives the market depth and availability of information. Business practices are well defined for participation in eBay and other transaction-oriented communities.

The connection between trust and contracts in transaction-oriented communities has been well studied. Of particular interest are the trust mechanisms built into eBay, Amazon and others. Ba and Pavlou, 2002 and Bolton et al., 2004 find strong evidence that rating systems do affect trust and that the effect of trust is stronger with more expensive items. Pavlou and Dimoka (2006) report that text comments significantly improve our understanding of price premiums. Dellarocus (2005) finds that eBay feedback mechanisms are almost able to maximize efficiency. Hu et al. (2004) describe a third party escrow service to mitigate the effects of risk.

Psychological contracts are closely related to social contracts and are useful and applicable to transaction-oriented communities. Psychological contracts are the beliefs a party has about the explicit or implicit reciprocal exchange agreement with another person (Rousseau, 1989 and Rousseau, 1995). In contrast, social contracts refer to the general population and what that group expects in return for 
the rights or freedoms forfeited. Pavlou and Gefen (2005) apply the theory of psychological contract violation in a survey of eBay and Amazon customers. Psychological contracts form from the understanding buyers and sellers have of the environment. They explain why users feel that the implicit contracts are violated even when the explicit promises are not and vice versa. They also find that the psychological contract violation has a negative impact on a buyer's trust of a group of sellers as do Bolton et al. (2004).

Business participation in transaction-oriented communities is the most welladopted and understood business practice in relation to virtual communities. A long-term approach to a transaction-oriented community requires an effort to keep feedback scores positive. Research shows that feedback scores have a positive impact on price premiums (Ba and Pavlou, 2002) and that negative feedback has a stronger impact on price than positive feedback (Bolton et al., 2004). Meeting and exceeding expectations of these contracts will contribute not only to buyers' sense of trust toward that individual but to a group of sellers in general (Bolton et al., 2004 and Pavlou and Gefen, 2005).

It is a common practice for retailers to liquidate old, aging or excess inventory on eBay or Overstock.com. Often the account used to liquidate inventory is not publicly connected to the real-world brand. Gefen (2000) finds that familiarity builds trust. Leveraging a real-world brand is likely to decrease or remove price penalties for risk. However, the benefits of lower price penalties must be balanced with risks of channel conflict if the brand is used online.

Interest-oriented communities gather users around a common theme such as Macintosh computers (www.macrumors.com), development on platforms (www.msdn.com) and support of products (support.dell.com). A salient social contract is the exchange of time and quality contributions for access to the information of the community. Users who create accounts to access information and never contribute may lose their account. If a user starts a threaded discussion that closely relates to a previous discussion, they will be told to move their comments to that previous discussion. This allows expert members to answer questions in one place. Individual members, and in some cases individual messages, are rated for their expertise and the quality of information they share such as in Experts-Exchange.com (www.experts-exchange.com).

If a user believes that advice given in an interest-oriented community is tainted by financial motives or lack of integrity, negative intentions or lack of benevolence, or does not come from a reliable source, indicating a lack of competence, the advice will be ignored. In worse cases, the user will be defamed or removed. Interest-oriented communities use social pressure and moderators to reduce negative contributions. Without close moderation, too many tainted contributions will kill the community. When participating in the community, businesses must be cautious that postings do not appear to have ulterior motives. Posts that seem to be tainted will damage the reputation of the 
business. Matching community and business needs can help to avoid this issue. To this point it is worthwhile to consider simple participation in a virtual community.

A business may also sponsor and govern an interest-oriented community. Sponsoring the community means supplying technical, knowledge, and administrative resources. When sponsoring a community, the business must dedicate sufficient resources to monitor the community and moderate its discussions. When posts come from a sponsor, the bar of untainted information is not held as high. Porter and Donthu (2008) find that a belief that a sponsor will act opportunistically does not have an effect on trust in this situation. This is because members of a sponsored community expect that the sponsor will use the community for its own purposes. Members understand the motivations of the sponsor when they join the community. These pre-set expectations effectively provide a different social contract.

Relationship-oriented communities generally focus on real-life relationships such as family (MyFamily.org) or business relations (Linkedln.com). However, in the last couple of years, sites such as MySpace.com allow, and even seem to encourage members to develop online relationships with community participants they have never met. One of the most important social contracts in a relationshiporiented community is that, in exchange for personal information, the user is assured that the information will be used properly. Relationship-oriented communities rely on real information to build real relationships. Users feel vulnerable or betrayed when their information is used for purposes beyond the scope of the community. This contract also implies that contact information is accurate. Accurate information and authenticity of contributions are vital because users will act on the information. The user is likely to go somewhere else if she does not believe that the community is capable of delivering accurate information about contacts or if information is not from an authentic source.

The lines between these communities can blur significantly. MySpace (www.myspace.com) was originally designed as a relationship-oriented community. Groups such as music bands began to list their band as a person in MySpace. The creators of MySpace have adapted this practice formally into the system. As members mark the band as a friend, they begin to form interestoriented groups. Interest-oriented communities may attract people for social support such as RevolutionHealth.com with its cancer forums. It is easy to imagine such a community developing into a relationship-oriented community as users come to create support groups.

Fantasy-oriented communities are seeing a surge over the last decade with the development of MMORPGs and recent popularity of virtual worlds such as Second Life. Over one million residents of Second Life were active in mid-2008 ( Second Life, 2008). Residents of Second Life are allowed to play out their fantasies in the community. Entertainment in fantasy-oriented communities has 
been compared to watching a movie of yourself ( Clemons et al., 2007). One of the strongest social contracts in these communities is that in exchange for time involved in the learning and participation, the virtual environment will be respected. In World of Warcraft, whether you are human, orc, or undead, you must stick to your role. Besides destroying the sense of reality, by not playing your role, you will make playing the game difficult for others. Residents of Second Life can quickly become offended when a third-party shares real-life information about another resident ( Carr and Pound, 2007).

Beyond the contract that focuses on the ability to escape reality, trust is not as vital for interaction in fantasy-oriented communities as it is in transaction-oriented communities. The social contract does not dictate that information must be perfect. Users often omit or falsify personal information. This reduces personal risk due to other community members' actions because interaction cannot move into the real world.

In some cases honesty is still expected. Private information is not generally shared in Second Life transactions, but residents still expect that items being sold are properly represented. When users willingly share personal information or engage in real transactions in fantasy-oriented communities, the lines between types of communities begin to blur. Users begin to need trust just as in transaction-oriented and relationship-oriented communities. Second Life transactions can have real economic implications for participants because Linden dollars, the currency in Second Life, can be exchanged into real currency.

Users of fantasy-oriented communities also expect that in exchange for their time, the environment will be interesting. When participating as a sponsor, a business must respect the desire of the user to enjoy the virtual environment. Wells Fargo's virtual world, Stagecoach Island, only displays the Wells Fargo logo in a couple of locations - on the virtual ATMs. Stagecoach Island is open to all and provides a way for young people to learn to manage their money. Wells Fargo management seems to use Stagecoach Island as an educational service they can provide to customers and potential customers more than as a marketing tool.

As a participant, the business must make itself part of the community. Dell Island in Second Life is an example of an elaborate and interesting creation. Dell Island is also one of few business ventures that can be perceived as successful to this point in time. The Senior Online Editor for Dell and Metaverse Evangelist, Laura Thomas, describes their approach and reason for this success: "We wanted to come in and add to the community, bring something there that people would enjoy. We tried to make sure the things we built there were very beautiful, that we weren't just putting up ugly billboards. We wanted to add to the community and the things that already exist there" (Thomas, 2008). 
Without an understanding of the social contracts of each community, businesses are likely to throw resources into virtual communities in an unsustainable manner. Much like the dotcom era, many companies seemed to be working on the attitude of "build it and they will come." Companies such as Coca-Cola and H\&R Block did not seem to understand the expectations of Second Life residents and thus did not create new and interesting entertainment for residents. Only after firms know how to participate within the boundaries of social contracts can they hope to find benefits in participation in these communities.

\section{HOW CAN BUSINESSES LEVERAGE VIRTUAL COMMUNITIES?}

Virtual communities can directly support most firm activities. The potential benefits of participation in virtual communities depend on individual firm characteristics and whether the activity is core to the firm. The value chain divides firm activities into primary activities and support activities. The characteristics of these two types of activities qualify them for different types of participation in virtual communities. Primary activities relate directly to the process of producing goods or services for sale. The major difference between primary activities and support activities in relation to virtual communities is the feasibility of sponsoring versus simple participation. Two key considerations need to be taken into account in assessing the feasibility of sponsoring a virtual community around a business activity. First, a critical mass of potential participants must be available. Because of network externalities that exist in virtual communities, the value of the community to any given individual increases as the number of participants in the community increases. There must be some critical point at which the community is valuable enough to attract and keep new members without external incentives. Current research has not yet defined the size of that critical mass. The second consideration is potential value for the sponsor. Support activities by nature are not directly related to the creation of goods or services. Primary activities on the other hand are directly related to goods and services and are often part of the core strategy and capabilities of an organization.

The following section discusses merits of participation and sponsorship in specific primary and support activities. The theory suggests that the following primary activities are the best candidates for sponsorship: product development, marketing, sales, and product support. Further, under appropriate conditions, all firm activities can be candidates to benefit from participation in virtual communities.

\subsection{Primary activities}

Primary activities can be candidates for sponsorship or participation. Firms whose customers are end consumers are more likely to have enough participants to sponsor an external virtual community. For these consumer-facing firms 
product development, marketing, sales, and support can benefit from community sponsorship as discussed in this section. On the other hand, logistics and operations management are less feasible candidates for sponsorship of an external community because firms have fewer parties involved in these activities. In the case of very large firms, logistics and operations management may also be feasible topics around which external communities may be sponsored (e.g., as the Wal-Mart suppliers discussing and solving logistics issues). For firms whose customers are not end consumers, product development, marketing, sales and support may fall into the same category as logistics and operations. These firms must be very large to have enough customers to base an external virtual community on primary activities. Harley-Davidson Supply Net is considered by some to be an example of these external communities ( Schneider, 2007). However, because sellers only interact with Harley-Davidson and not with each other, it seems more appropriate to characterize it as a simple e-commerce website rather than a virtual community in which users interact with each other.

When firms are large enough, all primary activities can potentially benefit from internal virtual communities. However, communities around logistics for a specific firm do exist. In 2003, Raytheon organized the Raytheon Integrated Community of Practice to bring together the logistics of seven departments. By 2005, Raytheon claimed cost savings of $\$ 50$ million ( BMPCE, 2005). In most cases, firms are not large enough to support internal virtual communities around logistics and operations. These activities are better candidates for participation in communities focused on general questions. Participation in an existing community can help firm employees answer difficult questions that arise in the day-to-day management of a firm. In an active community, firm employees can post a question and receive answers from individuals facing similar problems across the world. Examples of these are not difficult to find. Fleetxchange (www.fleetxchange.com) has been operating for at least 9 years. On Fleetxchange, individuals and organizations discuss their logistics issues from devices and machinery to opinions of shipping firms. Discussions on these types of communities are not focused on an individual firm but on issues that all interested parties face, such as the effect of different mud flaps on gas mileage.

\subsection{Product development}

Prosumerism is the involvement of the consumer in the development of new products. Involving the consumer in the development of the product helps a firm to develop products in accordance with customer desires and generate hype around the product. Several examples including the development of a car are discussed in Franz and Wolkinger (2003). New product development is an appropriate match with interest-oriented communities. In an interest-oriented community, members often want to be insiders. They want to be the first to know what the next product will be and what it will look like. Participants also want to know that their input is contributing to the design of products or the direction of the firm. When a participant sees that their ideas and suggestions create action 
on the part of the company, the participant feels like an insider ( Porter and Donthu, 2008).

The lesson from the social contracts of the interest-oriented groups is that these communities will remain active as long as they believe that the sponsor hears them and will keep them "inside" the group. The firm must dedicate sufficient resources to manage a community so that a representative of the sponsor can read and respond to all or most of the participants' ideas. Otherwise, the community may feel betrayed and leave, or worse, express negative feelings towards the sponsor through the community. Microsoft setup community forums for beta testers of Windows 7 (social.technet.microsoft.com/Forums/en/category/w7itpro/). On the Microsoft forum, it is difficult to find beta users unhappy with Microsoft's response to their feedback. Off of the community website, beta users are concerned that Microsoft does not seem to be responding to their feedback (Kennedy, 2009).

Not all product development initiatives are sponsored. The open source software community is an example of new product development by the users themselves (Franz and Wolkinger, 2003). One of the best-known communities is organized through SourceForge (www.sourceforge.net/community), which can be viewed as a group of interest-oriented communities. Each project or category of projects represents specific interests. Over 300,000 projects are arranged into twenty subcategories. Individual projects include Apache (a web server), MySQL (a database engine), 7-Zip (a file compression/decompression tool), and Openbravo (an enterprise system). Each project has a set of forums in which programmers and users can communicate, identify problems and resolve issues.

IS research has begun to explore the use of open source communities for commercial purposes (MacCormack et al., 2006 and Raghu et al., 2009). Research is not yet conclusive on this matter. When backed by an appropriate business model, open source development of products can be profitable. Red Hat is an example of a business based on open source development and has been in business for over 15 years (Red Hat, 2009). However, most business models cannot support open source development. When you sell a product developed under common open source licenses, you sell the code and rights to redistribute and make derivatives of the product. The product is also available to the community to reproduce. This kind of product development requires business models that revolve around support of the product or add-ons, which are not open source.

The business model Sun Microsystems had hoped to use after purchasing MySQL in early 2008 is built on both approaches. Sun announced its acquisition of MySQL in January 2008, effectively purchasing all of MySQL's clients which pay for support, including Facebook, Google, Yahoo!, and Nokia (MySQL 2005). The transaction was completed before the April 2008 Conference on MySQL, at which time Sun announce that certain features of the MySQL system, such as 
backup, would become closed source in version 6.0 (Cole, 2008). As well as an example of mixed business models, this is an example of conflicting social contracts. Open source developers participate in the project with the understanding that they will be able to use what they are building. Developing parts of the official project that are not open source threatens the position of the development community. On the other hand, Sun Microsystems obviously feels that they have a right to develop and sell extensions to MySQL. This has caused serious criticism of Sun from the open source community. In May 2008, Sun decided that it could not successfully follow this model and kept the whole project open source (Arno, 2009).

\subsection{Marketing}

Virtual communities are used for both advertising and building brand loyalty. There has been some success in this area; however, marketing in virtual communities is still very experimental in nature. Each type of community requires a different approach to marketing. In interest-oriented communities, loyalty can be built in two ways. As discussed earlier, interest-oriented communities focus their trust on the exchange of reliable and objective information. A sponsor must do its best to listen to the community and post clear, useful, reasonably objective information. If a sponsor tries to manipulate information or bulldoze community members that do not agree with it, members will find the information to be less reliable. The sponsor then risks the dissolution of the community.

Sponsorship of an interest-oriented support community can be a marketing tool as well as a support tool. The participants of a support community are likely to be repeat customers if they enjoy their experience. The sponsor will need to show effort to respond to the community either through posts, real-world action or both. Indeed, the best opportunities for a company to shine are through earnest responses to negative criticism. A great example comes from the Dell Community. In an article from Business Week, Jeff Jarvis wrote: "Terminally frustrated with a lemony laptop and torturous service, I vented steam on my blog under the headline: 'Dell sucks.' ... Thousands of frustrated consumers eventually commented on and linked to my blog, saying, 'I agree.' ... I blogged an open letter to Michael Dell suggesting his company read blogs, write blogs, ask customers for guidance, and join the conversation your customers are having without you" ( Jarvis, 2007).

In response, Dell developed "Idea Storm." Dell hired bloggers and technicians to answer questions and solve issues. Dell's blogs linked directly to the criticism and used responses to change customer service (Menchaca, 2007). This developed into Direct2Dell (direct2dell.com). Jeff Jarvis calls Dell's Chief Blogger a "credible human voice" for a large company (Jarvis, 2007).

Building loyalty through fantasy-oriented communities does not seem impossible, but has yet to prove very fruitful. Many Internet users have become desensitized 
to ads and do not recall seeing them (Clemons et al., 2007). Still an item or brand may become popular in a virtual community, and then spill over into the real world. This effect is not likely to be possible with most physical products. Brand loyalty with respect to fashions and fads in design may be a candidate for this kind of marketing though. Businesses attempting to build brand loyalty or advertise in virtual worlds need to know that they must continually offer something new or free to attract participants. Otherwise the virtual store will be empty. Many businesses that have entered Second Life have not been able to attract residents. According to Rose (2007), most Second Life accounts are abandoned because there is nothing new to do after you have walked around a bit.

In relationship-oriented communities, it is difficult to imagine many ways to develop brand loyalty. The example about how bands are using MySpace was already discussed. Another possible option is harvesting relationship information to allow businesses to find key social actors or hubs. If a firm can entice key actors to use or sponsor their product, they may be able to build some short-term loyalty to the product. This can be done for developing brand loyalty and advertising. Loyalty could last as long as the key actor continues to sponsor the product and as long as the key actor remains a key actor. If a key actor sponsors a product in too blatant a fashion though, she is likely to offend the circles in which she is respected and lose her status. Using information this way can have negative effects if not done appropriately. The social contract in most relationship-oriented communities dictates that information will be used for the purposes of the community. Business activities of this nature could cause participants who have real-world relationships to find new venues or return completely to the real world.

Advertising in interest-oriented communities and fantasy-oriented communities has been viewed from the marketing perspective as a gold mine of viral marketing. If this truly is the case, no one has discovered how to open the treasure chest. Interest-oriented communities are very sensitive to improper use of their resources. Trust is easily broken, and reputations are easily lost. Fantasy-oriented communities are not likely to look kindly on direct advertising if they notice the advertisements at all (Carr and Pound, 2007 and Clemons et al., 2007). Interest-oriented communities may discuss favorite brands, product quality and other commercially beneficial topics. On the other hand, if there appears to be any commercial participation before the discussion builds momentum, the topic will be interpreted as biased and of no value. Google Groups aggregates many community posts. It is possible that Google Groups have become less popular because many lists are polluted with outright advertisements. Searches for information on Google Groups, and thus on the many communities that it aggregates, often returns useless ads posted in the form of contributions to the community discussion. This obviously has a negative effect on the community. 
Garrett Hardin's (1968)tragedy of the commons applies to more than the interestoriented communities aggregated by Google. Advertising on many unsponsored communities is considered free or almost free. Management at Second Life has banned ad farms ( Krangel, 2008a). Ad farms are places where residents have built unattractive groups of ads. MySpace friend comments are plagued with advertisements, which do not contribute to the discussion of the person or group of interest. All of these forms of spam annoy users and make using the community for the intended purpose more difficult.

Advertising in transaction-oriented communities works well for a couple of reasons. First, participants spend money. Word ads or featured ads can produce results as long as the participants do not mentally or technically block ads. A second form of advertising is selling products at or below cost for exposure to the market. The obstacle to advertising on transaction-oriented communities is that when participants are ready to make a purchase, they are often focused on exactly what they want (Clemons et al., 2007).

\subsection{Sales}

Participation in transaction-oriented communities provides firms with access to a broader audience than is available through a physical store. However, precautions must be taken to manage channel conflict. In 2002, Accenture partnered with eBay to create an interface for large retailers to unload excess inventory in online auctions (BNET, 2002). Because of channel conflict issues, retailers may decide to have a third party such as Dealtree (www.dealtree.com) liquidate inventory for them in online auctions. Dealtree is a specialist in liquidation management that sells excess inventory on eBay. However, some retailers manage their own excess inventory on eBay. Circuit City used the name TradingCircuits to manage excess inventory on eBay.

Another flavor of transaction-oriented community allows consumers to use groupbuying power to request lower prices. eSwarm (www.eswarm.com), as of Spring 2009, provided buyers a place to express their desire for a product and price. Firms can then search eSwarm for customers interested in their products. Use of these types of communities has not yet become widespread. These communities provide consumers with lower prices and retailers with lower acquisition costs for customers. However, retailers and suppliers are not likely to use resources to search such websites until there are sufficient customers in the community expressing a desire for their products. Customers, on the other hand, are not likely to spend time using the website when the best example is the sale of putters to four customers of a swarm of seven consumers (eSwarm, 2008). Research on the growth of these communities could point to corrections which need to be made to make these communities mainstream.

Making transactions has been attempted through other types of communities. For a short period in 2006, Dell sold physical computers through the Second Life 
interface (Menchaca, 2006). However, updating the information and virtual objects involved in the selling the product proved too costly for the limited sales generated through Second Life. This may be possible at some future date when costs of configuration are lower or the demographic of a virtual world is more apt to make purchases through the virtual interface or both. Initially, the fact that Second Life residents are likely to be computer customers made entry into this market attractive. However, Second Life was not designed as a transactionoriented environment; therefore the residents were not inclined to buy computers through the virtual interface.

Clemons et al. (2007) suggests that information goods, such as music, may be a candidates for marketing through these interest-, fantasy- and relationshiporiented communities. One of the main obstacles to selling in virtual communities is that it is difficult to market information goods without giving them away. The obvious examples are clips of videos, songs, or individual tracks from an album. Copying branded intellectual property such as clothing and designs in Second Life has formed a virtual black market (Krangel, 2008b). A firm that wishes to sell information goods through virtual communities must trust that community participants are honest, be comfortable with the fact that the good may be given away, or provide a means of protection of the good.

\subsection{Product support}

Involving a community in product support reduces cost, speed and loyalty advantages. When users support other users, they solve each other's problems and leave a record for further use by users and the business. This relieves the business of some of the burden of more traditional support mechanisms. However, some costs must be borne by the sponsor to help the community find answers it cannot acquire on its own. The customer can benefit by obtaining immediate access to archived material. This allows customers to connect with other users who have dealt with the same issue and from whom they are likely to receive sympathy. As customers become more involved in a product support community, they are likely to become more loyal to that product and the sponsor. Moving to a different brand imposes two costs on the customer. First, switching costs of learning a new or unfamiliar product without the support of the community could be daunting. Second, users will suffer social costs in lost connections with the previous support group.

Involving a community in product support has several implications. First, a community is made of people with preferences and skills. For a product support community to be successful, the consumer base has to be comfortable using the computer and the Internet to find answers in the community. If this is not the case or if customers prefer direct communication with the sponsor, sufficient value will not be realized. Second, product support communities often cannot take care of themselves; they require attention from the sponsor. Many issues can only be addressed with the help of a specialist from the sponsor. If the sponsor does not 
address these issues, customers are likely to lose the community following or express negative feelings toward the company. When a discussion continues without resolution and without technician involvement, community users are likely to assume the sponsor is not attentive, does not care or is purposely hiding an answer. An example of this is a discussion of a power supply issue on Dell Community Forums that was never marked as solved, but had 79 posts (Dell Community, 2007).

Many uses of virtual communities are still experimental in nature. See Table 2. Virtual communities continue to develop and change. Fantasy-oriented communities currently seem too focused on encouraging their participants to live a fantastical life to enable businesses to successfully use them for other purposes (Fass, 2008). Part of the success of Dell and Wells Fargo in virtual worlds has been their ability to attract a new type of users to the medium. Participants who come to virtual worlds for mixed-reality meetings, computer support and educational purposes have different expectations and goals. If enough of those users join the world, they will eventually influence expectations and social contracts. This may open up new possibilities. Stagecoach Island and Dell support in Second Life bring customers into the virtual worlds that have interests more in line with the business objectives of the firm.

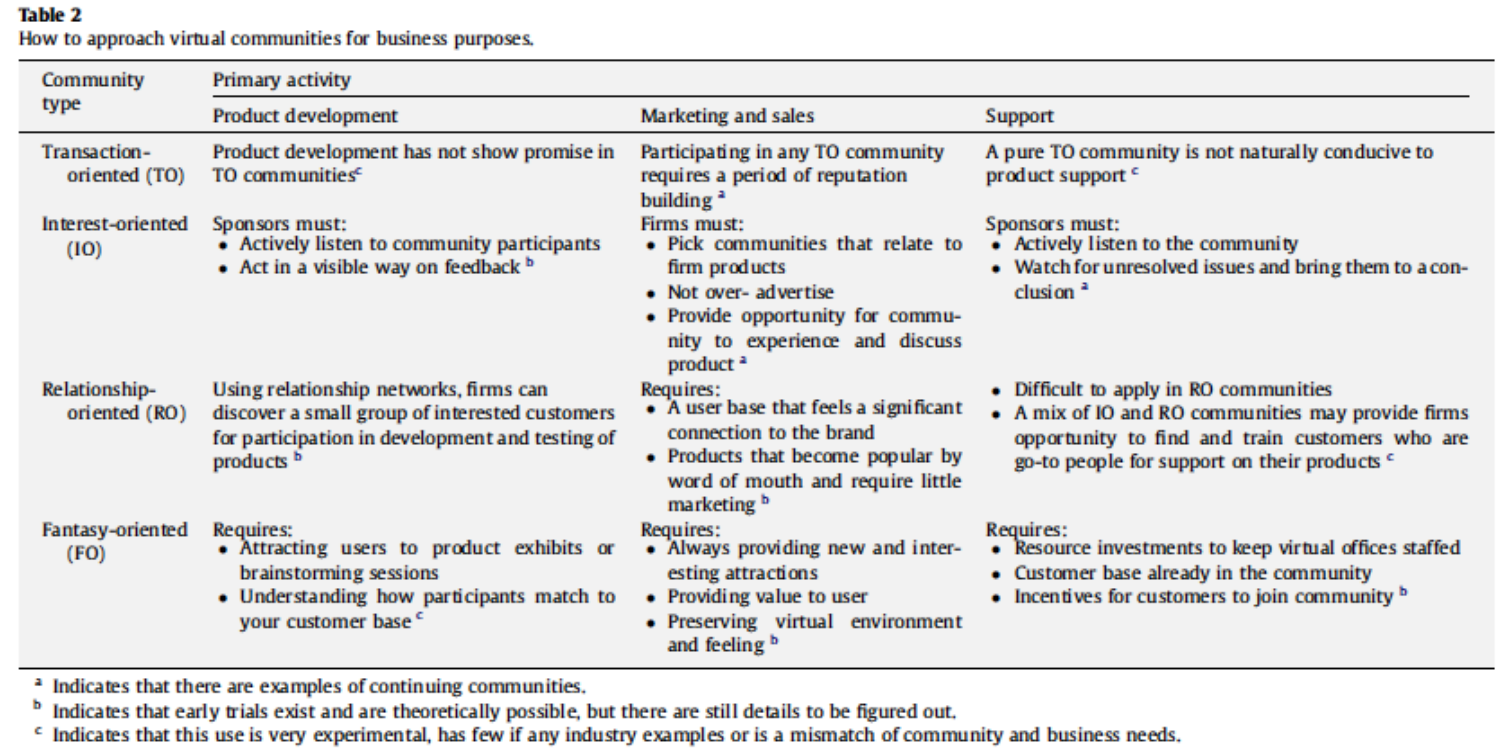

\subsection{Support activities}

The nature and purpose of support activities specific to an individual firm makes sponsoring a community around support activities difficult. Because support activities are internal by nature, they do not involve as many participants as 
primary activities. This makes building a critical mass more difficult. However, virtual communities do and have formed around support activities as they relate to more general processes and professions. Interest-oriented communities that address support activities act as centers of knowledge. Professional organizations or firms whose primary activities are delivery of support activities to other firms sponsor these communities. A good example of this is HR.com (www.hr.com). HR.com supports a group of professional human resources managers and workers. Members can share information on new research, problem-solving, and upcoming conferences and events.

Support staff involved in these interest-oriented communities will be informed in professional standards and current practices. Active participation will provide networking opportunities with industry professionals. As knowledge about the support disciplines advances in order to lower costs and meet the changing needs of the marketplace, support staff involved in the professional communities will be able to incorporate those changes into their firms. For example, if an HR professional is involved in a professional community, she will know of recent changes in hiring practices due to legislation and litigation. That knowledge will help her to decrease the risk of a lawsuit.

Open source communities make technology development somewhat different than the other support activities in that the community works together in production as well as knowledge dissemination and networking. In open source development, all interested parties can participate in the development of a technology. Indeed, many firms benefit from community-developed software such as the Apache web server and do not realize it. These are considered specialinterest communities that focus on specific technologies. An example is PSA Peugeot Citroën, the second-largest automobile manufacturer in Europe. The company contracted with Novell in January 2008 to set up 20,000 Linux desktops (Novell, 2007). Linux is continually updated and developed in the open source community.

Technology development is generally not conducive to sponsorship by an individual firm whose primary purpose is not technology development. Technically a firm could sponsor an open source project and community. However, in most cases when the project is successful, a spinoff organization will be created or the community will take the project. Open source enterprise software Openbravo (www.openbravo.com) and Compiere (www.compiere.com) are good examples. The first, Openbravo, was begun from two individuals' experiences in the mid-1990s with the development of software to manage a university. Those individuals founded Tecnicia in 2001 which later became Openbravo. The second comes from the original development of Compiere in 1999. In 2006 the community was dissatisfied with its ability to affect Compiere and thus created a fork called Adempiere (Adempiere, 2009). 
Two characteristics of the project must be considered when trying to build a community around firm software. First, some technologies are specific to a firm, which makes building a community around that software impossible. The technology in question has to be one that firms of many sizes and types must be interested in. Otherwise costs of maintaining the community can be prohibitively high. Second, some technologies may be usable by many organizations; however, they provide a firm with strategic advantage. Building a community around these systems can reduce those strategic advantages. As other organizations discover the technology through the community, they may use it or copy it and thus reduce the strategic advantage of the technology for the first firm.

Participation in virtual communities in connection with the activities of the value chain suggests several guiding principles for business participation in virtual communities. It also suggests several valuable areas of future research. Both are discussed in the following section.

\section{CONCLUSIONS}

This article has used social contracts and trust theory to help us understand how firms may successfully interact with a transaction-, interest-, relationship-, or fantasy-oriented communities. This was done from the perspective of the activities presented in the value chain. This section discusses a few guiding principles for success in participation with virtual communities according to these theories. However, this theoretical discussion leaves some very interesting and promising questions. This section ends by laying out the important questions to future research on firm participation in virtual communities.

\subsection{Principles for practice}

The application of social contracts theory and trust theory presents several principles to guide firm participation in virtual communities. The most important principle according to the theory of social contracts is to participate in the community within the bounds of the contract. The following suggestions all fit in the frame of this principle.

\subsubsection{Participation requires an attitude of contribution}

The marketing failure of businesses in the fantasy-oriented communities illustrates this well. The social contract of most communities is that each participant will add value to the community in one way or another. In fantasyoriented communities, that value is the creation of something interesting or new in the context of the community. The build-it-and-they-will-come concept does not apply here. HR Block and Coke did not do well in Second Life because they created a virtual presence and believed that residents would come (Rose, 2007). 
On the other hand, Dell created virtual backpacks, virtual trees, interesting architecture, historical replications and mixed reality meetings. Dell's Senior Online Editor, Laura Thomas, used the fact that Dell has not been subject to virtual terrorism or other protests as evidence that Dell has been able to fit into the culture of Second life (Thomas, 2008). This success comes from the Dell's attitude of contributing to the community. This attitude may stem from Dell's earlier failures such as the "Dell Hell" incident (Jarvis, 2007). Dell is one of the few real-life companies that have kept continued and positive interaction with residents of Second Life.

\subsubsection{The primary activity should not be advertising}

Marketing activities in interest-oriented communities require respect for both the social contract and the topic of interest. There is a temptation in interest-oriented or fantasy-oriented communities to advertise everywhere possible (Krangel, 2008a). Advertising only costs a business the time to post the ad. The consequence of such advertising is the negative impression created by polluting the forums and environments with unwanted material. This is akin to automated telephone calls to a home after 9:00 pm. Such calls can create negative feelings for the company. Advertising should be kept within the bounds allowed by the community. For example, Facebook includes the ability to create business pages and profiles. Interested customers can mark themselves as a fan of the business. For most businesses, simple presence is not enough though. Facebook also provides a pay-per-click advertising system for targeted ads. Participating within the boundaries set by the community will allow for long-term relationships with the community.

\subsubsection{Sponsoring a community requires resources}

The sponsor of a community is responsible to make sure sufficient value is found in the community to attract and keep new members. For example, a firm cannot assume that a support community will be able to solve all support issues on its own. Effort must be spent to find unresolved issues and contribute to the community. When implementing a product development or enhancement program, managers must be willing to let the community have a visible effect on firm action. If the community does not feel that it is having any influence on the brand they love, they may leave the community and possibly lose interest in the brand. This is evidenced by the open source enterprise system examples. Simple participation also requires resources, but often on a smaller scale. Participation in virtual communities is more like building strategic partnerships than like installing office productivity software. To implement office software requires an initial cost and then minimal support. A strategic partnership requires recognition of the other party's needs and existence and dedication to your common cause. A virtual community manager and consultant with 10 years experience stated, "I will keep saying it until it becomes common knowledge - communities are hard work. They take resources to design and plan, but more importantly, they take resources to maintain" (Johnston, 2007). 


\subsubsection{Be willing to experiment}

Participation of firms in virtual communities is a relatively new phenomenon. We still do not have empirical answers about how firms can participate. So experimentation can play a big role in discovering a firm's role in a community. According to Dell's Senior Web Editor, Laura Thomas, Dell's strategy has changed several times during Dell's time in Second Life and still provides mainly experimental value (Thomas, 2008). After sales through Second Life proved unreasonable, Dell offered customer support in Second Life and continues to offer it. Dell also successfully held mixed-reality events, in which real product launches or townhouse meetings are broadcast into Second Life, allowing residents to see the activities and participate in the community. Experimentation allows a firm to discover the social contract and learn to work in it.

\subsubsection{Match business and community needs}

Before embarking on a virtual community venture, managers must evaluate their company's business needs and how the social contracts of a candidate community fit with the business. For example, some firm cultures are not open to allowing the consumer to effect the final outcome of the engineers. Such firms are not a good fit with a product development community. Not every business has a need to build brand loyalty in interest-oriented communities or sell products in a transaction-oriented community. Virtual community users all have enough technical experience to participate in an online community. A firm's customer base may not match this demographic. However, there is almost always an interest-oriented community in which firms may participate for benefits in support activities. The obvious conclusion is that not all firms are good matches to virtual communities.

\subsection{Implications for future research}

Research opportunities that exist in one type of community may also exist in the others. However, each type of virtual community presents different research challenges because each community has its own social contract. It is worthwhile to categorize each research opportunity according to the type of community where the research is likely to have a significant impact on industry and theory. Transaction-oriented communities provide opportunities for research in the variation of social contracts and in the effect of social contracts on psychological contracts. Interest-oriented communities provide opportunity for research in attaining critical mass and a new perspective on trust in e-commerce. Relationship-oriented communities give researchers a fertile field for social network research including how to appropriately leverage different roles in the social network. Fantasy-oriented communities are experimental fields for advertising and the ability of a firm to affect the social contract. 
Transaction-oriented communities provide an environment for the study of two questions raised by the application of social contracts. First, what factors cause variation in social contracts? Although trust is well studied in the context of transaction oriented systems ( $\mathrm{Ba}$ and Pavlou, 2002, Dellarocus, 2005, McKnight et al., 2002 and Pavlou and Gefen, 2004), variation in social contracts has not been studied. The social contract is likely to be defined differently across different types of consumers, products and communities. For example, there are different communities of customers on eBay. Customers who frequently buy computer parts and supplies may be different from those purchasing automobiles. Financial risk to participants purchasing automobiles is greater than the risk faced by those purchasing computer parts. The social contract may therefore require that descriptions in automobile auctions are more thorough and that the bidder may have access to the item upon request. Differences also exist in the method and speed of payment, shipping and returns. What is standard in one community may not be standard in another community. This complexity can make entry into transaction-oriented communities difficult.

Research on the variation of social contracts across different characteristics of communities will provide theoretical and empirical evidence on how businesses can most successfully participate in transaction-oriented systems. Many anecdotal rules exist for how to participate successfully in transaction-oriented communities. Studying how product, consumer, and market characteristics affect the social contract can provide theoretical and empirical foundations for heuristics of participation in transaction-oriented communities. Research in online auctions has covered feedback mechanisms, text comments, escrow services, and psychological contract violation in an environment where the social contract is static (i.e., Ba and Pavlou, 2002, Dellarocus, 2005 and Pavlou and Gefen, 2005). Indeed, prior research depends on social contracts being the same across all observations. Understanding how social contracts vary is the next step in expanding and understanding how social contracts apply to IT. This understanding will also lay the foundation for evidence-based guidelines for practice.

The second question is what is the nature of the relationship between social contracts and psychological contracts? The theory of social contracts describes a group phenomenon. In a transaction-oriented community such as eBay, part of the social contract may be that immediate payment upon winning an item is a show of trust. Buyers then expect sellers to react quickly and positively in shipping and issue resolution. Psychological contracts refer to the explicit and perceived implicit promises of an individual transaction (Kaufman et al., 2005). A buyer's expectation that the seller will respond quickly to issues after shipment of a specific item because the buyer made immediate payment is part of a psychological contract. A new buyer may not be aware of the social contract and may thus hold off payment until requested by the seller or may not participate at all because of perceived risk. It is likely that psychological contracts come into 
agreement with social contracts as the participant gains more experience in community and thus comes to know the social contract.

Interest-oriented communities should be studied as both a phenomenon internal to the firm and external to the firm. One of the most difficult challenges in creating an internal community is reaching a critical mass. Costs of launch and maintenance of the community are higher when reaching a critical mass is slow. The costs of creating and administering these communities can be important because the benefits of these communities are lowering communication costs. What firm characteristics enable reaching a critical mass? Is the required size of the critical mass smaller in the context of certain firm and employee characteristics? Partial answers to these questions can be found in previous work in interest-oriented communities. However, previous research focuses more on encouraging the contribution of individuals ( $\mathrm{Ma}$ and Agarwal, 2007) and handling lurkers and trolls rather than reaching a critical mass ( Preece et al., 2004). Of course, if participants of a community are more likely to lurk or act as trolls, a larger critical mass is required to produce value in the community that will attract and keep new members.

Research on business participation in external interest-oriented communities must reverse a perspective taken in transaction-oriented community research. Most research related to transaction-oriented communities focuses on buyer trust of a seller (Ba and Pavlou, 2002, Dellarocus, 2005, Dellarocus, 2006 and Gefen, 2000 ) or buyer trust of the whole community of sellers (Bolton et al., 2004, Pavlou and Gefen, 2004 and Pavlou and Gefen, 2005). In interest-oriented communities, business outcomes focus on business reputation, marketing, or customer loyalty instead of individual transactions. Therefore, firms must know how to manage trust and reputation with the whole community. How do the expectations of firms change depending on their role in the community or place in the social network? Research has already shown that when the sponsor participates in a community though content contribution, the social contract is more lenient (Porter and Donthu, 2008). It may be expected that individuals representing a firm would be expected to disclose their affiliation in every post or when giving advice. In some social positions on the periphery of the network, firms may be required to make quality contributions which do not directly promote firm services or products. Knowing which roles are most trusted and which are most lenient to advertising in interest-oriented communities will enable business to participate effectively without offending or harming a community.

A third area of research in interest-oriented communities is social contract engineering. Firm have several methods that may be feasible to affect the evolution of a social contract. First, a sponsor firm may include seeds of the social contract in a user agreement. Second, simple participation in the community may affect the social contract, especially if the firm is the first firm to enter the community. Actions of the firm during this time may set precedence for how similar users will participate or if the community will allow such users into the 
community. Finally, firm participation in a virtual community may attract customers to the community. Under certain circumstances, these new users will affect the development of the social contract.

Relationship-oriented communities provide opportunity for viral marketing through interpersonal relationships. However, a community does not always pick up on a firm's product without any effort on the part of a firm. Using social networking techniques firms may locate important community members. They can then offer those members goods, services, or special treatment in exchange for reviews of those goods and services. Comments that are judged to have different levels of bias may have different effects on the standing of the member that made the comments. The feasibility of this kind of activity is largely unknown. Before recruiting community members to introduce a firm into the community, the firm should know the effect of such actions on the standing of the member in the community.

The record left by relationship-oriented and interest-oriented communities can also be used for market research. For example, Kozinets (2002) collected data over 33 months from a community of coffee lovers. Without the record of the virtual community, this process is time-intensive, requiring the researcher to read the titles of each thread of discussion. Using automated collection agents, market research could become much more efficient. Such agents have been used to collect large amounts of data to understand market mechanisms in online auction research (Kauffman et al., in press and Wood and Kauffman, 2005). Such agents can be used to enhance research in social contracts. Internet agents used to collect information from virtual communities should follow standard ethics (Allen et al., 2006) and design principles (Kauffman et al., 2000). The data collected can then be used in design science work to develop market research tools.

Fantasy-oriented communities are still relatively new. Current research and business use of fantasy-oriented communities is very experimental in nature. Research on fantasy-oriented communities has begun to appear in IS conferences and practitioner-oriented literature (Clemons et al., 2007, Kim et al., 2008 and Parise and Guinan, 2008). A couple of interesting questions arise given the social contract to respect the environment of the online community. First, if we assume that participation in fantasy-oriented communities will broaden to include target advertising audiences, we can ask what type of advertising in fantasy-oriented communities will be successful. Anecdotal evidence suggests that some Internet users do not see traditional ads when they are placed on search pages. It is possible that ad space in fantasy-oriented communities may be practically invisible to users immersed in the fantastical experience. If an ad can become part of the experience, it is much more likely to produce positive results. In 2006 Toyota opened a dealership to sell virtual Scions in Whyville and Second Life ( Goodstein, 2006). Residents could customize the cars and drive their friends around in them. Though this kind of advertising provides name brand recognition, it is not exactly experiential advertising. A resident cannot actually 
feel how the car drives, taste the soft drink or see how the jeans fit. Experiential advertising in fantasy-oriented worlds may be limited to information type goods. Researchers should design effective business activities around these types of marketing strategies.

Second, can the activities of a business change the social contract? The largest obstacle to using fantasy-oriented worlds is that residents do not wish to participate in real-life activity and often are not of the same demographic as firm customers (Clemons et al., 2007). Dell's use of Second Life for technical support and to hold mixed reality meetings attracts new residents with different expectations. When users join Second Life with the purpose of interacting with a firm, they are using the virtual community as a meeting place rather than an immersive fantasy. Dell can then produce real-world benefits from the virtual community such as solutions to customers' technical questions and improved attendance at town hall meetings. Firms may be able to change the social contract by simple participation and patience. If this is feasible, real-world firms could draw real value from participation in fantasy-oriented communities.

\subsection{Concluding comments}

Research on business use of virtual communities has the potential to be both timely and timeless. Many businesses are currently failing in their attempts to use virtual communities. After 2 years of active coverage of Second Life events, Reuters is pulling out of Second Life (Pasick, 2009). The Gartner report on social technologies puts the public use of virtual worlds near the bottom of the trough of the hype cycle (Gartner, 2008). Now is the time to lead industry in finding answers to the question of how businesses should participate in virtual communities. For firms to succeed in using virtual communities they must respect social contracts. On the one hand, social contracts enable businesses to participate in communities. On the other, they can limit what activities are feasible. Participating according to the community's social contract allows the business to develop trust with the community.

\section{Acknowledgments}

I thank my doctoral colleagues Degan Kettles, Yong Jick Lee, Arti Mann, Daniel Soper, Hina Arora, and Aaron Baird for their thoughtful input and reviews. Especially, I thank the special issue co-editors, and Rob Kauffman for his direction and input throughout the development of the ideas and paper. I also acknowledge the input from Laura Thomas at Dell inc. and Steven Angelo at Linden Lab for their valuable input. 


\section{REFERENCES}

Adempiere. Project charter; 2009. <http://www.adempiere.com/wiki/index.php/ Project_Charter>. Adempiere community website (last accessed on 07.09.09).

Akerlof, G. A. The market for lemons: quality uncertainty and the market mechanism. Quart J Econ, 84, 3, 1970, 488-500.

Allen, G. N., Burk, D. L., and Davis, G. B. Academic collection in electronic environments: defining acceptable use of Internet resources. MIS Quart, 30, 3, 2006, 599-610.

Arno K. MySQL: MySQL Server is open source, even backup extensions; 2009. $<$ blogs.mysql.com/kaj/2008/05/06/mysql-server-is-open-source-evenbackupextensions> (last accessed 07.09.09).

Ba, S., and Pavlou, P. Evidence of the effect of trust building technology in electronic markets: price premiums and buyer behavior. MIS Quart, 26, 3, 2002, 243-268.

BMPCE. Best manufacturing practices center of excellence: Raytheon integrated logistics community of practice; 2005. <http://www.bmpcoe.org/bestpractices/ internal/rayid/rayid_10.html (last accessed on 07.09.09).

BNET. eBay connects with Accenture to move excess inventory online; 2002. <http://findarticles.com/p/articles/mi_m0FNP/is_10_41/ai_86204708> (last accessed on 07.09.09).

Bolton, G. E., Katok, E., and Ockenfels, A. How effective are electronic reputation mechanisms? An experimental investigation. Manag Sci, 50, 11, 2004, 1587-1612.

Carr, P., and Pound, G. The unofficial tourists' guide to second life: the essential guide to a virtual world with millions of users. St. Martin's Press, New York (NY), 2007.

Clemons, E. K., Barnett, S., and Appadurai, A. The future of advertising and the value of social network websites: some preliminary examinations. In M. Gini and R. J. Kauffman (eds.), International conference on electronic commerce, Minneapolis, MN, ACM Press, New York, NY (USA), 2007.

Cole J. Just announced: MySQL to launch new features only in MySQL Enterprise; 2008. <http://jcole.us/blog/archives/2008/04/14/just-announcedmysql-tolaunch-new-features-only-in-mysql-enterprise/> (last accessed 07.09.09). 
Dellarocus, C. Reputation mechanism design in online trading environments with pure moral hazard. Inform Syst Res, 16, 2, 2005, 209-230.

Dellarocus, C. How of ten should reputation mechanisms update a trader's reputation profile. Inform Syst Res, 17, 3, 2006, 271-285.

DellCommunity. Latitude power management; 2007. <http://www.dellcommunity. com/supportforums/board/message?board.id=latit_power\&message. $i d=7902 \&$ query.id=249567-M7902> TX: Dell Inc., Round Rock (last accessed on 07.09.09).

DellCommunity. Welcome to Dell Community; 2008. <http://www.dell.com/ community>. TX: Dell Inc., Round Rock (last accessed on 07.09.09).

Deutsch, M. Trust and suspicion. J Conflict Resol, 2, 4, 1958, 265-279.

eSwarm. Why suppliers love to eSwarm; 2008. <http://www.eswarm.com/index. php?module=welcomesuppliers\&tab=stories $>$ (last accessed on 07.09.09).

Fass A. Sex, pranks and reality. Forbes; July 2, 2008. <http://www.forbes.com/home/free_forbes/2007/0702/048.html> (last accessed on 07.09.09).

Fishbein, M., and Ajzen, I. Belief, attitude, intention and behavior: an introduction to theory and research. Addison Wesley, Reading (MA), 1975.

Franz, R., and Wolkinger, T. Customer integration with virtual communities: case study: the online community of the largest regional newspaper in Austria. In R. $\mathrm{H}$. Sprague (ed.), Proceedings of the 36th Hawaii international conference on systems sciences, Kona, HI, IEEE Computing Society Press, Los Alamitos (CA), 2003.

Gartner Staff. Hype cycle for social software. G00158239. CT: Gartner Inc. Stamford; 2008 [August 1].

Gefen, D. E-commerce: the role of familiarity and trust. Omega, 28, 6, 2000, 725-737.

Goodstein A. My so-called virtual life. BusinessWeek; December 4, 2006. <http:// www.businessweek.com/technology/content/dec2006/tc20061204_056163.htm> (last accessed on 07.09.09).

Hardin, G. The tragedy of the commons. Science, 162, 1968, 1243-1248. 
Hu, X., Lin, Z., Whinston, A. B., and Zhang, H. Hope or hype: on the viability of escrow services as trusted third parties in online auction environments. Inform Syst Res, 15, 3, 2004, 236-249.

Jarvis J. Dell learns to listen. BusinessWeek; October 17, 2007 (last accessed on 07.09.09).

Johnston B. OC Expert interview: Joi Podgorny, Ludorum, Inc.

OnlineCommunity-Report,; September 12, 2007.

$<$ http://www.onlinecommunityreport.com/archives/257-OC-Expert-Interview-JoiPodgorny,-Ludorum,-Inc.html> (last accessed on 07.09.09).

Kannan, P. K., Chang, A.-M., and Whinston, A. B. Electronic communities in e-business: their role and issues. Inform Syst Front, 1, 4, 2000, 415-426.

Kauffman, R. J., March, S. T., and Wood, C. A. Design principles for long-lived Internet agents. Int J Intell Syst Account Finance Manag, 9, 4, 2000, 217-236.

Kauffman RJ, Spaulding TJ, Wood CA. Are online markets efficient? An empirical study of market liquidity and abnormal returns in online auctions. Decis Support Syst; in press.

Kaufman, J. H., Edlund, S., and Ford, D. A. The social contract core. Electron Commerce Res, 5, 1, 2005, 141-165.

Kee T. The second life hype has fizzled - is twitter next? Forbes; February 20, 2009. <http://www.forbes.com/2009/02/20/second-life-hype-fizzles-technology_ paidcontent.html> (last accessed on 07.09.09).

Kennedy RC. Windows 7: cutting corners in the rush to market? InfoWeek; February 19, 2009. <http://www.infoworld.com/d/windows/windows-7-cuttingcornersin-rush-market-975> (last accessed on 07.09.09).

Kerin, R. A., and Sethuraman, R. Exploring the brand value-shareholder value nexus for consumer goods companies. J Acad Mark Sci, 26, 4, 1998, 260273.

Kim, H. M., Lyons, K., and Cunningham, M. A. Towards a framework for evaluating immersive business models: evaluating service innovations in second life. In R. H. Sprague (ed.), Proceedings of the 41st annual Hawaii international conference on system sciences, IEEE Computing Society Press, Los Alamitos (CA), 2008.

Kozinets, $\mathrm{R}$. V. The field behind the screen: using netnography for marketing research in online communities. J Mark Res, 39, 1, 2002, 61-72. 
Krangel E. Premium accounts decline in June. Reuters; August 31, 2007. <http:// secondlife.reuters.com/stories/2007/08/31/premium-accounts-decline-in-july/>. Author working under pseudonym Eric Reuters (last accessed on 7.09.09).

Krangel E. Linden Lab bans extortionate ad farms. Reuters; February 14, $2008 \mathrm{a}$. $<$ http://secondlife.reuters.com/stories/2008/02/14/linden-lab-bans-extortionateadfarms/>. Author working under pseudonym Eric Reuters (last accessed on 7.09.2009).

Krangel E. Virtual retailers decry second life crime wave. Reuters; February 7 , 2008b. <http://secondlife.reuters.com/stories/2008/02/07/virtual-retailersdecrysecond-life-crime-wave/>. Author working under pseudonym Eric Reuters (last accessed on 07.09.09).

Lewicki, R. J., McAllister, D. J., and Bies, R. J. Trust and distrust: new relationships and realities. Acad Manag Rev, 23, 3, 1998, 438-458.

Ma, M., and Agarwal, R. Through a glass darkly: information technology design, identity verification and knowledge contribution in online communities. Inform Syst Res, 18, 1, 2007, 42-67.

MacCormack, A., Rusnak, J., and Baldwing, C. Y. Exploring the structure of complex software designs: an empirical study of open source and proprietary code. Manag Sci, 52, 7, 2006, 1015-1030.

McKnight, D. H., Choudhury, V., and Kacmar, C. Developing and validating trust measures for e-commerce: an integrative typology. Inform Syst Res, 13, 3, 2002, 334-359.

Menchaca L. Dell gets a second life; 2006. <http://en.community.dell.com/blogs/ direct2dell/archive/2006/11/14/3555.aspx> (last accessed on 7.09.09).

Menchaca L. Jeff Jarvis: Dell hell: the end? 2007.

<http://direct2dell.com/one2one/archive/2007/10/18/31956.aspx> (last accessed on 07.09.09).

Novell. PSA Peugeot Citroën chooses SUSE Linux Enterprise desktop from Novell; 2007. <http://www.novell.com/news/press/psa_peugeot_citro_eumln_ chooses_suse_linux_enterprise_desktop_from_novell> (last accessed on 07.09.09).

Parise, S., and Guinan, P. J. Marketing using web 2.0. In R. H. Sprague (ed.), Proceedings of the 41st annual Hawaii international conference on system sciences, Kona, HI, IEEE Computing Society Press, Alamitos (CA), 2008. 
Pasick A. The Reuters second life bureau is now closed. Reuters; March 2, 2009. $<$ http://secondlife.reuters.com/stories/2009/03/02/the-reuters-second-lifebureauis-now-closed/>. Author working under pseudonym Adam Reuters (last accessed on 07.09.09).

Pavlou, P., and Dimoka, A. The nature and role of feedback text comments in online marketplaces: implications for trust building, price premiums, and seller differentiation. Inform Syst Res, 17, 4, 2006, 392-414.

Pavlou, P., and Gefen, D. Building effective online marketplaces with institutionbased trust. Inform Syst Res, 15, 1, 2004, 37-59.

Pavlou, P., and Gefen, D. Psychological contract violation in online marketplaces: antecedents, consequences, and moderating role. Inform Syst Res, 16, 4, 2005, 372-399.

Porter, C. E., and Donthu, N. Cultivating trust and harvesting value in virtual communities. Manag Sci, 54, 1, 2008, 113-128.

Preece, J., Nonnecke, B., and Andrews, D. The top five reasons for lurking: improving community experiences for everyone. Comput Hum Behav, 20, 2, 2004, 201-223.

Raghu, T. S., Sinha, R., Vinze, A., and Burton, O. Willingness to pay in an open source software environment. Inform Syst Res, 20, 2, 2009, 218-236.

Red Hat. Corporate fact sheet for Red Hat; 2009. <http://www.redhat.com/about/ companyprofile/facts/>. Red Hat Inc. in Raleigh, NC (last accessed on 07.09.09). Reuters. Reuters official page in second life; 2008. http://secondlife.reuters.com/ (last accessed on 07.09.09).

Rheingold, $\mathrm{H}$. The virtual community: homesteading on the electronic frontier. Harper Perennial Publishers, New York (NY), 1993.

Rose F. How Madison Avenue is wasting millions on a deserted second life. Wired; July 24, 2007. <www.wired.com/techbiz/media/magazine/15-08/ff_sheep? currentPage $=1>$ (last accessed on 07.09.09).

Rousseau, D. M. Psychological contracts in organizations. Employee Responsibil Rights J, 2, 2, 1989, 121-139.

Rousseau, D. M. Psychological contracts in organizations. Sage Publications, Thousand Oaks (CA), 1995.

Rousseau, D. M., Sitkin, S. B., Burt, R. S., and Camerer, C. Introduction to special topic forum. Acad Manag Rev, 23, 3, 1998, 393-404. 
Rousseau JJ. The social contract; 1762. <http://www.constitution.org/jjr/socon. $\mathrm{htm}>$ (last accessed on 07.09.09).

Schneider, G. Electronic commerce, 7th ed.. Thomson Course Technology, Boston (MA), 2007.

Second Life, 2008. Economy statistics. <secondlife.com/statistics/economy-data. php> (last accessed on 07.09.09).

Smith, M. A. Communications in cyberspace. Routledge, New York (NY), 1999. Thomas L. Personal interview. Senior online editor. TX: Dell Inc., Round Rock; 2008 [April 23].

Vivendi Annual financial report and audited consolidated financial statements for the year ended; 2007 [December 31]. <http://www.vivendi.com/vivendi//MG/ pdf/20080401_Financial_Report_Year2007.pdf> (last accessed on 07.09.09). Wood, C. A., and Kauffman, R. J. The effects of shilling on final bid prices in online auctions. Electron Commer Res Appl, 4, 1, 2005, 21-34. 